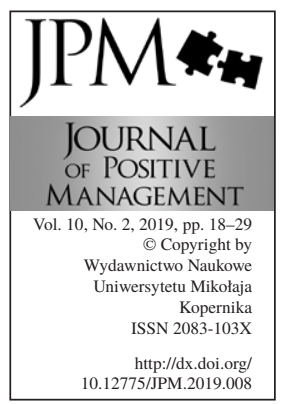

\title{
SOURCES OF IMPROVEMENT OF USERS' COMPETENCIES WHILE CLOUD SOLUTIONS ARE BEING INTRODUCED INTO MANUFACTURING COMPANIES
}

\author{
Magdalena Zalewska-Turzyńska \\ University of Lodz, Faculty of Management, Lodz, Poland \\ e-mail: mzalewska@uni.lodz.pl
}

\begin{abstract}
Cloud computing as a relatively new information and communication technology (ICT) introduces a change in the way companies conduct business by offering them new opportunities. Organizations operating on the market that decide to implement cloud computing solutions in their daily work must take into account the size of the changes. Such a change, although it seems to be only a technological change, also affects the change of the company's technological processes, which is not without an impact on the organization of the company, also causing changes in its structure. In the face of such extensive changes in the company, the competences of employees must also change. The research question posed for the purpose of this study concerns the methods of acquiring new competences by employees, necessary in the face of a change in the organization in the form of the implementation of cloud solutions for everyday work. The results of the conducted research indicate that the most commonly used method is the training of key users (used in 59.25\% of the 400 companies surveyed). Other significant statistical data are presented in the article.
\end{abstract}

Purpose: The research question posed for the purpose of this study concerns the methods of acquiring new competences by employees, necessary in the face of a change in the organization in the form of the implementation of cloud solutions for everyday work in Polish production companies.

Methodology: The CATI survey (computer-assisted telephone interviewing) was used as the research method with the return rate of $0.7966 \%$ (400 companies).

Findings: The results of the conducted research indicate that the most commonly used method is the training of key users (used in $59.25 \%$ of the surveyed companies). Only 0.0225 of the surveyed companies use "other" methods than the proposals listed in the survey to improve competences (key users training, all users training, learning by reading manuals and e-learning training), which leads to questions about the reason for such a low diversity of introduced methods.

Implications/limitations: The conducted research helps to determine the method of raising the competences most frequently used by companies during cloud implementation. Outcomes also allow practitioners to customize the training offer of competences rising directed to key users. 
The type of necessary competences may be an important criterion for choosing the method of obtaining them - this needs verification. Moreover covid situation has changed attitude towards remote methods of raising employee competences (this also needs further research).

Originality/value: This paper contains the results of research on the methods chosen by employers to raise employee competences when implementing cloud solutions in Polish manufacturing companies.

Keywords: cloud computing, rising competencies, manufacturing companies

\section{Introduction}

Cloud computing is a reasonably recent development in information and communication technology (ICT). It is changing the way industries and enterprises do their businesses. It also offers new opportunities for enterprises (Xu, 2012). Organizations operating on the market which decide to implement cloud computing solutions in their daily work must take into account the size of the changes. Such a change, although it seems to be only a technological one, also affects the change of the company's technological processes, which is not without impact on the organization of the company by causing changes in its structure. In the face of such extensive changes in the company, the competences of opponents must also change. The research question posed for this study concerns ways of acquiring new competencies by employees, necessary in the new situation and necessary in the face of a change in the organization which is the implementation of cloud solutions for everyday work. Competency is in this article understood as a minimum standard, a threshold that must be achieved or as behaviour that individual demonstrates and that contributes to success (Mitchelmore and Rowley, 2010).

\section{Theoretical background}

The name Cloud Computing was inspired by the cloud symbol that is often used to represent the Internet in flow charts and diagrams (Zissis, 2012). Among academics and researchers, there is still no agreement over the definition of Cloud Computing concept and solutions, therefore, a few are presented below.

The definition of the cloud computing model introduced by the U.S. National Institute of Standards and Technology (NIST, 2009) is: "A model for enabling ubiquitous, convenient, on-demand network access to a shared pool of services (for example, networks, servers, storage, applications and services) that can be rapidly provisioned and released with minimal management effort or service provider interaction". The NIST definition recognises the availability of cloud computing and describes its five essential characteristics: on-demand self-service; broad network access; resource pooling; rapid elasticity; and measured service 
SOURCES OF IMPROVEMENT OF USERS'

Magdalena Zalewska-Turzyńska
(NIST, 2009). This one is probably most frequently used, one of the oldest and therefore with time may be adopted as binding.

There are also other definitions, for example - cloud computing "aims to provide access to the information and the data from anywhere at any time by restricting or eliminating the need for the hardware equipment (Rahimi et al., 2014). Cloud Computing could be also defined as "a distributed information technology (IT) architecture in which client data is processed at the periphery of the network, as close to the originating source as possible" (Stergiou et al., $2018 b)$. These definitions outline essential characteristics as storage over the Internet, service over the Internet, application over the Internet, energy efficiency and computational capability. (Stergiou et al., 2018a).

Over the years, studies on Cloud Computing (CC) have focused on the much-needed technical aspects of cloud implementation (Brender and Markov, 2013; McGeogh and Donnellan, 2013; Garg et al., 2013), CC features (Pearson, 2013) in terms of advantages (Senarathna et al., 2018; Saini et al., 2019) and disadvantages (Rong et al., 2013), security (Stergiou et al., 2018a), way of using CC in terms of security (Jones, 2015) and privacy (Li et al., 2018), Cloud provider (Abdel-Basset et al., 2018), capacity of cloud provider (Qiu et al., 2018), service models (SaaS, PaaS, IaaS - Balco et al. 2017; Penzel et al., 2017, and also model DaaS - Dillon and Chang, 2010; Puthal et al., 2015) and next generation of CC (Varghese and Buyya, 2018). Other authors define an architectural framework and principles for energy-efficient cloud computing (Beloglazov et al., 2012) or adopting CC in terms of companies goals, growth and competitiveness (Shuaib et al., 2018).

Moreover, in the case of clouds adoption, there is a lack of unified approach to measuring adoption with studies leveraging Diffusion of Innovation (DOI), Technology-Organization-Environment (TOE), Human-Organization-Technology fit (HOT-fit) theory, Information Processing View (IPV), and Technology Acceptance Model (TAM) for understanding cloud adoption in the computing context (Lynn et al., 2018).

Business perspective implies that the most important factor for business is its client's satisfaction. When companies move their business activities to the cloud, it seems that new skills are needed for their employees. This is not only technical competence but competences connected to the core process of the organization. Employee competencies are the source of the company's competitive advantage and have a positive impact on the company. The importance of competencies to organizations cannot be overemphasized; in fact, they are the key to competitive advantage. For an organization to succeed in its goal, organizational competencies must match strategic intent. Without the needed competencies strategies cannot be successfully implemented and realized (Ranjbarfard et al., 2018). 
TOE theory, apart from the influence of organizational factors, such as firm size or technology readiness, also explores employee competence, and top management support (Lian et al., 2014).

The HOT-fit model incorporates organizational and technological dimensions with human factors, it states that user attitude and also competencies have a positive impact on technology adoption. Cloud computing adoption by an organization is also influenced (Lian et al., 2014) by organizational and technological factors (e.g. data security and technological complexity) and also by the human factor which is, among others, perceived as technical competence.

Lynn, Liang, Gourinovitch, Morrison, Fox, Rosati (2018) categorized the influential decisions factors in cloud computing adoption into four groups: The first is human factors such as the personal innovativeness of key decision-makers and perceived technical competence and training. The second are organizational factors including the adequacy of resources, top management support, perceived indirect benefits, and relative advantage. The third is technological factors such as perceptions of the innovation's complexity, compatibility, and security. Fourth are environmental factors such as competitive pressure, government policy, and partner support. This is symptomatic that competencies are listed in the first group. They (Lynn et al. 2018) also posit that technical competence would be a significant determinant of adoption for HPC (SaaS, PaaS or IaaS).

Since competences are so important for the organization's success, the question arises - what is the source of gaining competencies to fulfil requirements of shifting to a cloud solution. Where are the competences taken from in the face of change?

Broad conceptual paper on competences was presented by Hafkesbrink and Schroll (2010) in which they presented a link between organizational and individual competences in open innovation processes. Unfortunately they do not indicate sources of acquiring competences. Ala-Mutka (2011) states that attention must be paid to ensure that everyone has digital competence as it provides important benefits while its lack can lead to various risks. Presented conceptual model has objective of highlighting the various knowledge, skill and attitude areas that should be considered when developing digital competence - however, it omits the sources of their acquisition. Results of research covering ways to acquire ICT competences were presented by Ahmed and Rehman (2016). They researched the level of ICT competencies, and the training needs for updating these competencies among library professionals in Khyber Pakhtunkhwa in Pakistan. The findings was that self-study was main avenue of acquiring ICT skills. In Poland, these problems were not covered by the research, the research results presented in this article allow to broaden knowledge in this area.

Therefore the research question is formulated as follows: what are the sources of employee competences that they absorb when introducing an organizational 
SOURCES OF IMPROVEMENT OF USERS'

Magdalena Zalewska-Turzyńska change in the form of cloud solution implementation for daily work in production organizations in Poland.

\section{Research method and sample}

The investigation was conducted in 2018 in Poland. The CATI survey (computerassisted telephone interviewing) was used as the research method. The phone calls were directed to 50212 companies, the return was from 400 firms, therefore the return rate equals $0.7966 \%$.

The selected Polish organizations were targeted based on three criteria - size, sector and condition that the cloud solution is being used in the company on a regular basis. The size criterion imposed a choice of minimum 50 organizations from each size group: micro (employing up to 9 persons), small (from 10 to 49 people), medium (50 to 249 employees) and large (employment above 250). The sample consists of 50 micro-companies (12.50\%), 81 small companies $(20.25 \%)$, 146 medium companies $(36.50 \%)$ and 123 large enterprises $(30.75 \%)$.

The second and third criteria were simply 'yes' or 'no' answers, in case of 'no' the company was excluded from the research. The sector criterion (the second one) was imposed only on production companies. The criterion of regular usage of clouds in daily work (the third one) is met - all companies use clouds for work, but 181 of them use clouds only for mailing purposes whereas 219 use it for a wider range of possibilities. Finally, there was no need to exclude any company from the research.

Moreover, company's market activity in terms of turnover was established the sample consists of $4.75 \%$ of local companies (area of the county), $3.25 \%$ of regional (area of the voivodship), $28.25 \%$ of national and $63.75 \%$ of international companies.

Respondents were asked about methods used to increase competences. A cafeteria of suggestions for methods of raising competencies was presented in the form of a list that consisted of key users training, all users training, learning by reading manuals and e-learning training. Moreover, there was also an option of supplementing the proposed cafeteria with other, not mentioned, methods used in companies. Respondents most frequently pointed at the method of key users training, this is in $56.25 \%$ of cases. They rarely mentioned other methods than proposed by the researcher. See Figure 1 below that summarizes the answers.

Respondents could point to more than one method of improving competencies, but $63.50 \%$ of companies use only one method of competence improvement, see Figure 2 below. A quarter of researched companies pointed 2 answers. Altogether, statistically, it gives 1.47 methods per company in the researched group.

There was also the category "other" to be filled in by respondents. It was not a popular one, among those methods supplemented by respondents exactly 9 answers were found for 400 companies answering the question. These individual 

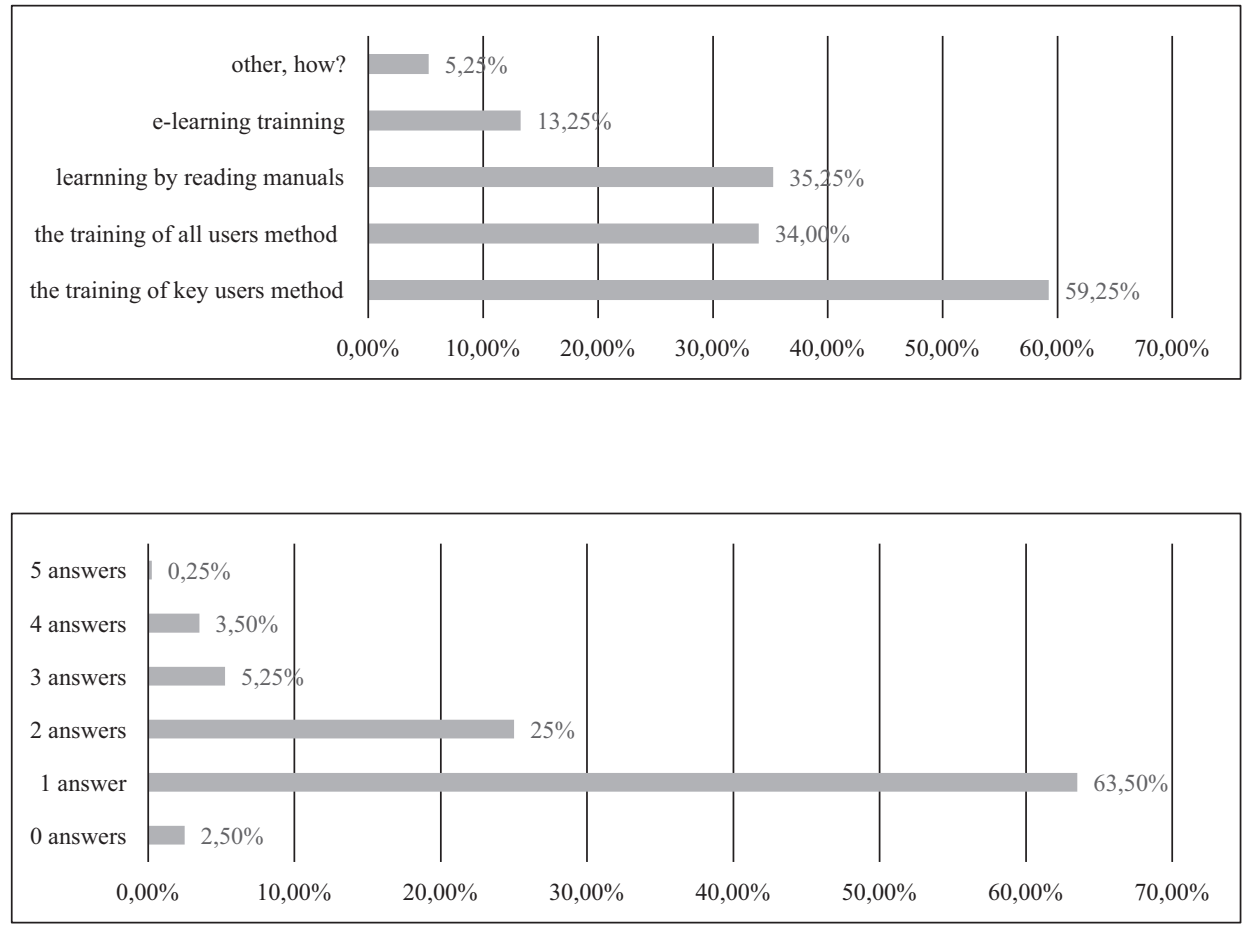

cases were: coaching, the company does not care about the employee, not acquired in the country, outsourcing, I will train myself, self-study, self-training without the use of an IT system, training users who have an internal benefit, internal training.

\section{The results}

After collecting the data they were coded and processed by SPSS, a statistical package system. Results were analysed and summarized to help with drawing conclusions.

In investigating significant difference, the Pearson Chi-square test of independence was used. All the presented Chi-square results are significant; post-hoc analysis is then conducted for identifying significant differences at the 0.05 level. The outcomes of the research are presented in the figures below. Only statistically significant correlations are presented.

There is a weak but significant correlation between organization scope and the key users training method used for improving competencies. More of the international companies use the method of key users training $(36.75 \%)$ than do not use this method at all $(27.00 \%)$, whereas in the companies of national scope $2 / 3$ use this method (19.00\%) and $1 / 3$ do not use it $(9.25 \%)$. In the case of local
SOURCES OF IMPROVEMENT OF USERS'

Magdalena Zalewska-Turzyńska

Figure 1. Ways in which users are acquiring competencies in the field of cloud solutions in companies

Source: own research.

Figure 2. The number of selected answers denotes the frequency of using the designated methods

Source: own research. 
SOURCES OF IMPROVEMENT OF USERS'

Magdalena Zalewska-Turzyńska

Figure 3. The training of key users method versus organization scope

Source: own research.

Figure 4. The training of all users method versus organization scope Source: own research. companies, there is deuce between usage of the key users training method and not using this method at all. The results are presented in Figure 3 below.

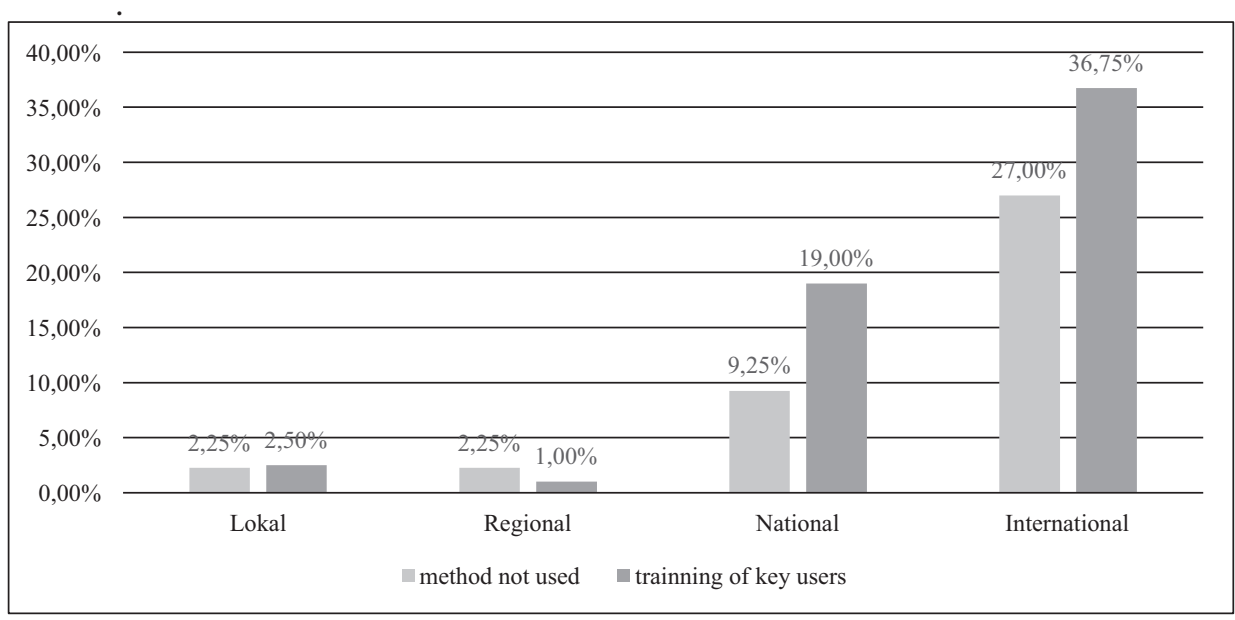

Person Phi-square $\mathrm{P}=0,046 \quad \mathrm{~V}$-Crammer $=0,046$

There is a weak but significant correlation between organization scope and method for improving competencies used, in the form of all users training. The method of all users training is altogether less frequently used in companies than key users training - in numbers $59.25 \%$ to $34.00 \%$. That is the explanation why fewer companies train all users than do not train them by this method at all. More of the international companies do not use this method $(43.47 \%)$ than use it

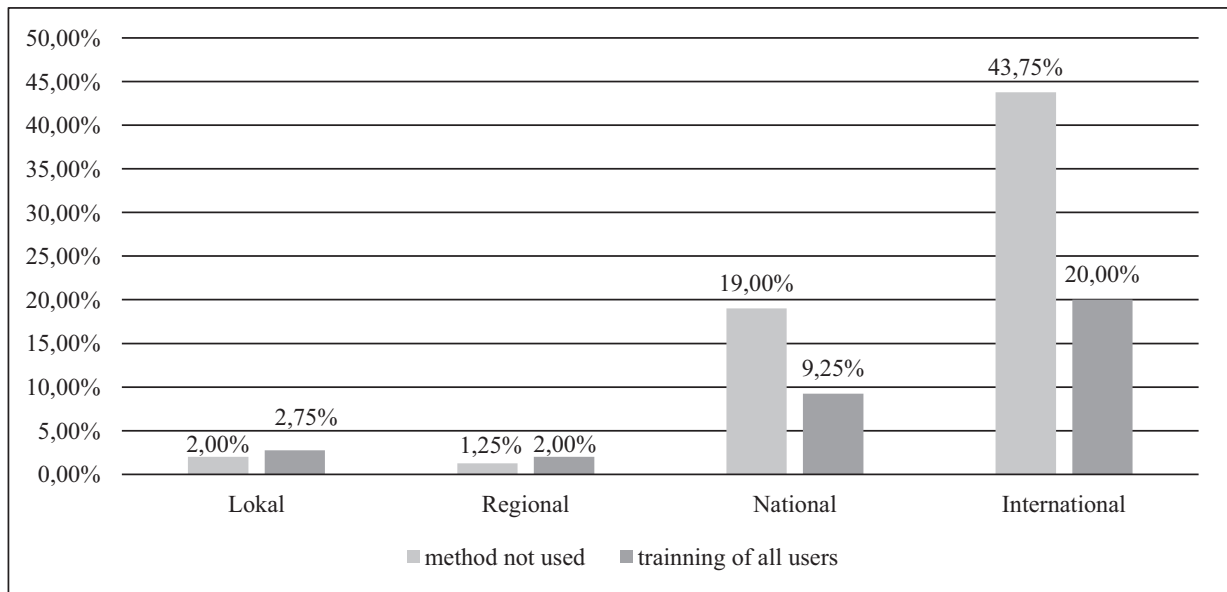

Person Phi-square $\mathrm{P}=0,018 \quad \mathrm{~V}$-Crammer $=0,018$ 
(20.00\%), similar proportion is for national companies $(19.00 \%$ to $9.25 \%)$. Whereas the proportion of using this method to not using it in the case of local and regional companies is different - more companies train all users then do not use this method.

In the research, it was established weather the company uses clouds only for post purposes or the clouds are used in different scopes. One of the reasons for that was an assumption that companies using clouds only for post purposes train their employees less frequently by any method than second group. However, there is no such dependence. Both groups use method of key users training with similar (at first glance) frequency, the differences are small and seen at closer look. In the case of companies using clouds for more than post purposes, $57.5 \%$ train the key users, $42.5 \%$ do not use this method. In the case of companies using clouds only for post purposes, the numbers are $61.3 \%$ and $38.7 \%$ respectively. The outcomes show that the method of key users training is even more frequently used in companies that use clouds for post purposes than in companies that use clouds to wider range of duties. This war surprising for the researcher and did not confirm the expectations set before the research. The detailed values are presented below in Figure 5.

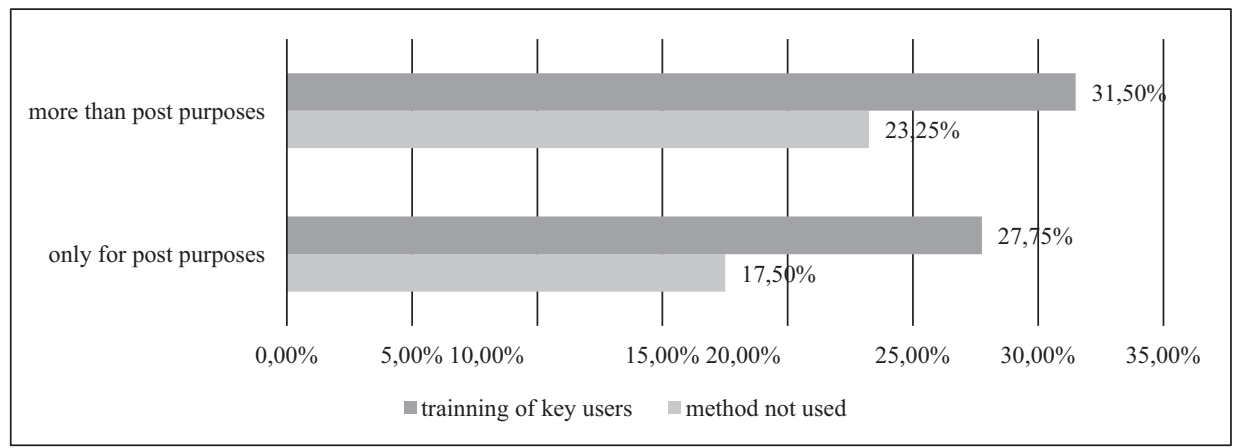

Person Phi-square $\quad \mathrm{P}=0,038 \mathrm{~V}$-Crammer $=0,038$

In the case of companies that use clouds for post purposes only $31.49 \%$ use a training method of teaching all users, while in companies using clouds for more purposes than post, the percentage of trained all users is $36.07 \%$. The details are presented below in Figure 6.

In the case of learning by reading manuals, the method is more frequently used (than not) in the case of companies using clouds for more than post purposes comparing to companies that use clouds only to post purposes $36.53 \%$ and $33.70 \%$ values respectively. The detailed numbers are presented below in Figure 7.
Figure 5. The training of key users method versus the purpose of the cloud

Source: own research. 
SOURCES OF IMPROVEMENT OF USERS'

Magdalena ZalewskaTurzyńska

Figure 6. The training of all users method versus the purpose of the cloud

Source: own research.

Figure 7. Learning by reading manuals method versus the purpose of the cloud

Source: own research.

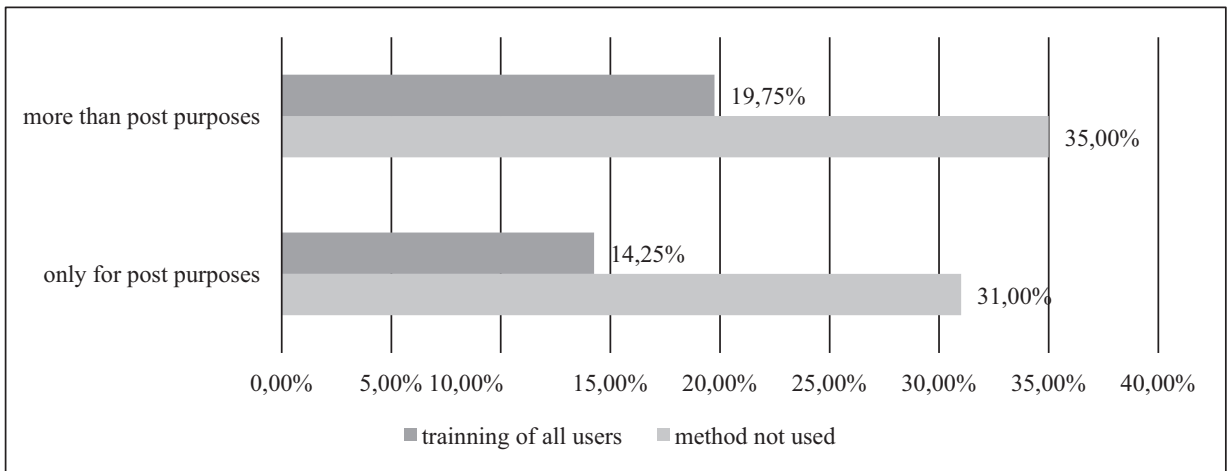

Person Phi-square $\mathrm{P}=0,048 \quad \mathrm{~V}$-Crammer $=0,048$

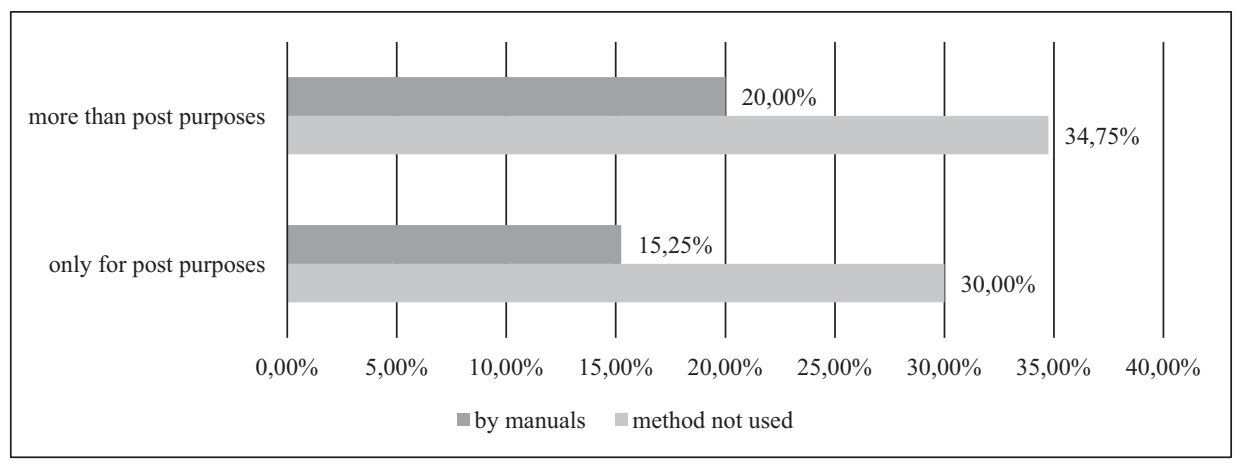

Person Phi-square $\mathrm{P}=0,029 \quad \mathrm{~V}$-Crammer $=0,029$

The dominant way to acquire competence is - as it is seen on the Figures above - is the training of key users. This method is used in $59.25 \%$ of the 400 companies surveyed.

\section{Conclusion}

In the context of the research question regarding the sources of acquisition of competences by employees during the organizational change which is the transfer of certain utilities to the cloud in Polish production enterprises, it should be stated that:

1. Training of key users method was used most frequently in international companies, and companies that use clouds for more than post purposes.

2. Training of all users method was used most frequently also in the case of international companies, but only $1 / 3$ of researched international companies use this method $-2 / 3$ do not use it. 
3. Companies using clouds for post purposes use key users training method more often than companies using clouds in broader range of possibilities.

4. Companies using clouds for post purposes use all users training method less often than companies using clouds in broader range of possibilities.

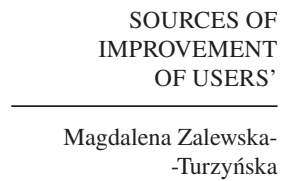

5. Learning by reading manuals is used more often by companies that use clouds for more than post purposes.

6. Researcher expected a vast variety of answers filled in the line "other". But there were only 9 answers from 400 companies. It only may imply a poor repertoire of methods used by companies for raising qualifications or reluctance in filling in the questionnaire.

7. It was expected that the company size has strong, significant dependence on the method used by the company to train their employees while introducing cloud computing to daily routines. Meanwhile, according to this study, such dependence does not exist.

The conducted research helped to determine the method of raising the competences most frequently chosen and used by companies during cloud implementation. At the theoretical level, research indicates that competencies in organizations are increased in a diffusive way (like knowledge) by key participants. If there is no blockage in the flow, it should reach all employees with the help of key employees as a distribution point - but this is only an assumption, the success of which is fraught with many factors (predictable and described in literature and unpredictable). Nevertheless this outcomes allow practitioners to customize the training offer of competences rising directed to key users and managing (or even force) its diffusion.

In the context of conducted research and presented outcomes the further investigation should concentrate on identification of key competences that employees should have. The type of necessary competences may be an important criterion for choosing the method of obtaining them. In addition, key competences in the use of ICT technology may also condition the efficient implementation of solutions.

This article was written in December 2019 before the covid-19 pandemic. Currently (June 2020), the repeat and broaden research is underway to investigate whether, in the face of remote work, there has been a change in the way of acquiring and transferring competences related to the necessity of moving to the cloud imposed by the pandemic situation.

\section{References}

Abdel-Basset, M., Mohamed, M., Chang, V. (2018), "NMCDA: A framework for evaluating cloud computing services", Future Generation Computer Systems, Vol. 86, pp. 12-29. 
SOURCES OF IMPROVEMENT OF USERS'

Magdalena Zalewska-Turzyńska
Ala-Mutka, K. (2011), Mapping digital competence: Towards a conceptual understanding, Institute for Prospective Technological Studies, Sevilla.

Ahmed, S., Rehman, A.U. (2016), "Perceptions and level of ICT competencies: a survey of librarians at public sector universities in Khyber Pakhtunkhwa, Pakistan", Pakistan Journal of Information Management and Libraries, Vol. 18 No. 1, pp. 1-11.

Balco, P., Law, J., Drahošová, M. (2017), “Cloud market analysis from customer perspective", Procedia Computer Science, Vol. 109, pp. 1022-1027.

Beloglazov A., Abawajy J., Buyya R. (2012), "Energy-aware resource allocation heuristics for efficient management of data centers for Cloud computing", Future Generation Computer Systems, Vol. 28 No. 5, pp. 755-768.

Dillon, T., Wu, C., Chang, E. (2010), “Cloud computing: issues and challenges", in: $24^{\text {th }}$ IEEE international conference on advanced information networking and applications, pp. 27-33.

Hafkesbrink, J., Schroll, M. (2010), “Organizational Competences for open innovation in small and medium sized enterprises of the digital economy", Competence Management for Open Innovation: Tools and It Support to Unlock the Innovation Potential Beyond Company Boundaries.

Jones, S. (2015), "Cloud computing procurement and implementation: Lessons learnt from a United Kingdom case study", International journal of information management, Vol. 35 No. 6, pp. 712-716.

Li, P., Li, J., Huang, Z., Gao, C.Z., Chen, W.B., Chen, K. (2018), "Privacy-preserving outsourced classification in cloud computing", Cluster Computing, Vol. 21 No. 1, pp. 277-286.

Lian, J.W., Yen, D.C., Wang, Y.T. (2014), “An exploratory study to understand the critical factors affecting the decision to adopt cloud computing in Taiwan hospital", International Journal of Information Management, Vol. 34 No. 1, pp. 28-36.

Lynn, T., Liang, X., Gourinovitch, A., Morrison, J.P., Fox, G., Rosati, P. (2018), "Understanding the determinants of cloud computing adoption for high performance computing", in: $51^{\text {st }}$ Hawaii International Conference on System Sciences (HICSS-51), University of Hawai'i at Manoa.

Mitchelmore, S., Rowley, J. (2010), "Entrepreneurial competencies: a literature review and development agenda", International journal of entrepreneurial Behavior \& Research, Vol. 16 No. 2, pp. 92-111.

Pearson, S. (2013), "On the relationship between the different methods to address privacy issues in the cloud", in: OTM Confederated International Conferences "On the Move to Meaningful Internet Systems", Springer, Berlin, Heidelberg, pp. 414-433.

Penzel, D., Kryvinska, N., Strauss, C. (2017), "Cloud Market - Analysis of Potentials and Challenges for Service Providers", The 23rd Americas Conference on Information Systems (AMCIS 2017), Boston, USA, August 10-12, 2017, Workshop on Smart Manufacturing, Special Interest Group on Big Data Proceedings (SIGBDA).

Puthal, D., Sahoo, B.P., Mishra, S., Swain, S. (2015), "Cloud computing features, issues, and challenges: a big picture", in: 2015 International Conference on Computational Intelligence and Networks, pp. 116-123.

Qiu, C., Shen, H., Chen, L. (2018), “Towards green cloud computing: Demand allocation 
and pricing policies for cloud service brokerage", IEEE Transactions on Big Data, Vol. 5 No. 2, pp. 238-251.

Rahimi, M.R., Ren, J., Liu, C.H., Vasilakos, A.V., Venkatasubramanian, N. (2014), "Mobile cloud computing: A survey, state of art and future directions", Mobile Networks and Applications, Vol. 19 No. 2, pp. 133-143.

Ranjbarfard, M., Heidari Sureshjani, M. (2018), "Offering a framework for value cocreation in virtual academic learning environments", Interactive Technology and Smart Education, Vol. 15 No. 1, pp. 2-27.

Rong, C., Nguyen, S.T., Jaatun, M.G. (2013), "Beyond lightning: A survey on security challenges in cloud computing”, Computers \& Electrical Engineering, Vol. 39 No. 1, pp. 47-54.

Saini, H., Upadhyaya, A., Khandelwal, M.K. (2019), "Benefits of Cloud Computing for Business Enterprises: A Review", available at SSRN 3463631.

Senarathna, I., Wilkin, C., Warren, M., Yeoh, W., Salzman, S. (2018), "Factors That Influence Adoption of Cloud Computing: An Empirical Study of Australian SMEs", Australasian Journal of Information Systems, Vol. 22, pp. 1-31.

Shuaib, M., Samad, A., Alam, S., Siddiqui, S.T. (2018), "Why Adopting Cloud Is Still a Challenge? A Review on Issues and Challenges for Cloud Migration", Ambient Communications and Computer Systems: RACCCS-2018, Vol. 904, pp. 387-399.

Stergiou, C., Psannis, K.E., Kim, B.G., Gupta, B. (2018a), "Secure integration of IoT and cloud computing", Future Generation Computer Systems, Vol. 78, pp. 964-975.

Stergiou, C., Psannis, K.E., Gupta, B.B., Ishibashi, Y. (2018b), "Security, privacy \& efficiency of sustainable cloud computing for big data \& IoT", Sustainable Computing: Informatics and Systems, Vol. 19, pp. 174-184.

Varghese, B., Buyya, R. (2018), "Next generation cloud computing: New trends and research directions", Future Generation Computer Systems, Vol. 79, pp. 849-861.

Zissis, D., Lekkas, D. (2012), “Addressing cloud computing security issues”, Future Generation computer systems, Vol. 28 No. 3, pp. 583-592. 